\title{
(6) OPEN ACCESS \\ Self-reported patient safety competence among new graduates in medicine, nursing and pharmacy
}

\author{
Liane R Ginsburg, ${ }^{1}$ Deborah Tregunno, ${ }^{2}$ Peter G Norton ${ }^{3}$
}

\begin{abstract}
- An additional appendix is published online only. To view this file please visit the journal online (http://dx.doi.org/10. 1136/bmjqs-2012-001308).

${ }^{1}$ School of Health Policy and Management, York University, Toronto, Ontario, Canada ${ }^{2}$ School of Nursing, York University, Toronto, Ontario, Canada

${ }^{3}$ Department of Family Medicine (Emeritus), University of Calgary, Calgary, Canada
\end{abstract}

\section{Correspondence to}

Dr Liane R Ginsburg,

School of Health Policy and

Management, York University,

HNES Bldg Rm 413, 4700 Keele

Street, Toronto, Ontario,

Canada M3J 1P3;

lgins@yorku.ca

Received 25 June 2012

Revised 9 October 2012

Accepted 16 October 2012

Published Online First

23 November 2012

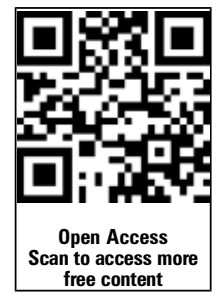

To cite: Ginsburg LR, Tregunno D, Norton PG. BMJ Qual Saf 2013;22:147-154.

\begin{abstract}
Background As efforts to address patient safety (PS) in health professional (HP) education increase, it is important to understand new HPs' perspectives on their own PS competence at entry to practice. This study examines the selfreported PS competence of newly registered nurses, pharmacists and physicians.
\end{abstract}

Methods A cross-sectional survey of 4496 new graduates in medicine (1779), nursing (2196) and pharmacy (521) using the HP Education in PS Survey (H-PEPSS). The H-PEPSS measures HPS' self-reported PS competence on six socio-cultural dimensions of PS, including culture, teamwork communication, managing risk, responding to risk and understanding human factors. The $\mathrm{H}$ PEPSS asks about confidence in PS learning in classroom and clinical settings.

Results All HP groups reported feeling more confident in the dimension of PS learning related to effective communication with patients and other providers. Greater confidence in PS learning was reported for learning experiences in the clinical setting compared with the class setting with one exception-nurses' confidence in learning about working in teams with other HPs deteriorated as they moved from thinking about learning in the classroom setting to thinking about learning in the clinical setting. Conclusions Large-scale efforts are required to more deeply and consistently embed PS learning into HP education. However, efforts to embed PS learning in HP education seem to be hampered by deficiencies that persist in the culture of the clinical training environments in which we educate and acculturate new HPs.

Several key international bodies have made recommendations to restructure how we educate health professionals (HPs) to ensure they are properly equipped with the knowledge, skills and attitudes required to practice safely. ${ }^{1-6}$ This requires introduction and integration of patient safety (PS) content into HP curricula and training programmes, with a particular emphasis on the socio-cultural facets of PS. ${ }^{1}$ Restructuring HP education is challenging ${ }^{7}$ and a growing literature suggests it is occurring very slowly across the health professions. ${ }^{4}$ 8-12

As efforts to include PS in HP education increase it is important to capture trainees' and new HPs' perspectives of their own PS knowledge and competence. ${ }^{1}$ There are a number of published studies that have examined trainees' PS knowledge, skills and attitudes. Most of these studies have reported on assessments of the impact of specific PS curricular or training interventions. ${ }^{13-26}$ However, these studies have been largely confined to a single educational institution, and have been limited to a single HP group.

A much smaller set of studies have examined PS knowledge, skills and attitudes of more than one HP group. ${ }^{27-29}$ These studies have focused on areas such as methods of effectiveness for delivery of inter-professional education, ${ }^{29}$ learning uniprofessionally or multi-professionally, ${ }^{28}$ or they have used qualitative approaches. ${ }^{30} 31$ Additionally, we were only able to find three studies that examined PS learning in the classroom and clinical settings. One was a small pilot study, ${ }^{23}$ one focused on the formal, informal and hidden aspects of curricula, ${ }^{32}$ and all three were limited to a single HP group. ${ }^{23} 2432$ This paper reports on data concerning the safety educational experience gathered from newly licensed/ registered nurses, pharmacists and physicians from across Canada's most populous province, Ontario.

\section{METHODS}

We conducted a large, cross-sectional survey of new graduates in medicine, 
nursing and pharmacy using the HP Education in PS Survey (H-PEPSS). ${ }^{33}$ The H-PEPSS is a validated tool that measures HPs' self-reported PS competence. The study was conducted in the fall of 2010 in the Canadian province of Ontario, which has six medical schools, 15 nursing schools and two training programmes for pharmacists, all of which are housed in publicly funded universities. At the time of data collection one of the pharmacy programmes was new and did not yet have graduates.

\section{Sampling and procedures}

The inclusion criteria for the sample were nurses, medical doctors and pharmacists who received registration/licensure with their relevant regulatory college in Ontario, Canada in 2010 (this was expanded to 2009 or 2010 for the pharmacy and postgraduate medicine groups to yield a sufficient sample for these two groups); completed their degree in a Canadian university during the preceding 1 year period; and provided their college with an email address. In the case of the physicians there were two groups: those who had just finished medical school (the MD group); and those who had just completed a residency (the postgraduate medicine group). The resulting sample consisted of 814 in the MD group, 965 in the postgraduate medicine group, 2196 registered nurses and 521 pharmacists. All 4496 members of the sample were invited to participate in this study.

The relevant professional college (the College of Physicians and Surgeons of Ontario, College of Nurses of Ontario, the Ontario College of Pharmacists) sent an email invitation to take part in the survey along with a link to the survey webpage. Following recommendations for electronic surveys ${ }^{34}$ two reminder invitations were sent out 1 and 2 weeks after the initial invitation. Survey invitations were drafted by the research team and were consistent for all three professional groups. To allow for anonymous survey completion, no trackable links were used. We were aware of the historically poor survey response rates from practicing HPs and in an attempt to ameliorate this we offered two draws, each one for an iPad. However, respondents had to provide their email address if they wished to be entered into one of these draws. Completed survey data were retrievable only by one of the study investigators (LG) who is not affiliated with any of the regulatory colleges. The study received approval from the Human Participants Review Committee in the Office of Research Ethics at the lead author's home institution (York University).

\section{Survey instrument}

Study data were gathered using the H-PEPSS. ${ }^{33}$ The H-PEPSS measures HPs' self-reported PS competence and was designed to reflect six socio-cultural areas fundamental to PS and central to a number of key PS competency frameworks developed by various international professional bodies and WHO. ${ }^{5} 3536$ A systematic review ${ }^{37}$ published just prior to publication of the H-PEPSS found no existing surveys that measured the breadth of content reflected in these safety competencies.

The psychometric properties of the H-PEPSS are described elsewhere ${ }^{33}$ and support a 16-item measure of self-reported PS competence that reflects six dimensions: Working in teams with other HPs (three items), Communicating effectively (three items), Managing safety risks (three items), Understanding human and environmental factors (two items), Recognising and responding to adverse events (two items), and Culture of safety (three items). For all six dimensions, $\alpha$ s range from 0.81 to 0.85 . Items begin with the stem 'I feel confident in what I learned about...' and are answered using a five-point disagree-agree Likert-type scale and include a 'don't know' option. For each item, respondents are asked to respond separately about their confidence in what they learned in the classroom setting versus the clinical setting (given the structure of postgraduate medical training, this group is only asked about the clinical setting). Survey items in each dimension are shown in online appendix 1. Mean dimension scores are calculated from the items in each dimension for each learning setting (eg, you will have a score for confidence in learning around Communicating effectively based on education provided in the classroom and a separate score for confidence in learning around Communicating effectively based on education provided in the clinical setting). The H-PEPSS begins by asking about confidence in knowledge of four more clinical aspects of safety (eg, hand hygiene and infection control). These items are included in the H-PEPSS solely to help respondents distinguish between clinical and socio-cultural aspects of PS so they can focus on the latter.

\section{Analysis}

Study analyses were carried out using basic descriptive and inferential statistics: H-PEPSS dimension means were compared; one-way analysis of variance (ANOVA) was used to compare H-PEPSS dimension scores across the different HP groups in the study; and paired $t$ tests were used to examine differences in confidence in PS learning in the class setting compared with learning in the clinical setting for each H-PEPSS dimension. All analyses were carried out using SPSS V.19.

\section{RESULTS}

\section{Respondents}

Of the 4496 new graduates invited to complete the H-PEPSS, 180 had undeliverable email addresses or were terminated at the survey website for failing to meet the study eligibility criteria outlined above. A total of 1247 out of 4316 eligible new graduates 
submitted an online survey resulting in a response rate of $28.9 \%$ overall, with slight variation by respondent group $(\mathrm{MD}$ group $=35 \%$, postgraduate medicine $25 \%$, pharmacy $29 \%$ and nursing 28\%). Summary data provided by the relevant colleges indicate that the respondent group is representative of the target population in terms of age (mean age $=27.5)$, gender $(55 \%$ women for both medicine groups, $70 \%$ for pharmacy and 91\% for nursing) and training institution, with one exception-those who trained in a Canadian jurisdiction outside of Ontario are slightly underrepresented in the respondent group. Data from 1102 responders who responded to more than $50 \%$ of the items in each H-PEPSS dimension are included in the analyses reported here.

\section{Comparing H-PEPSS dimensions}

To compare self-reported PS competence across the H-PEPSS dimensions, dimension means are compared and reported in table 1. Column B shows dimension means (as measured on a five-point scale ranging from 1 ('strongly disagree') to 5 ('strongly agree')) for selfreported confidence in learning in the classroom and clinical setting for all HP groups combined. Based on non-overlapping 95\% CIs (not shown), respondents' self-reported PS competence in the Communicating effectively dimension is significantly higher than selfreported PS competence in the Working in teams with other HPs dimension, the Managing safety risks dimension and the Understanding human and environmental factors that influence safety dimension. This pattern holds true for all HP groups and for confidence in learning in the classroom and clinical settings with one exception (for learning in the clinical setting pharmacists are equally confident in the learning around Effective communication and Understanding human and environmental factors that influence safety).

\section{Differences between HP groups on the H-PEPSS}

One-way ANOVA was used to test for differences in self-reported PS competence across the different HP groups in the study. For learning in the classroom setting (comparing mean scores in table 1), nurses scored significantly higher than the pharmacy and MD groups on all dimensions $F(\mathrm{df}=2,870) F$ ranges from 17.45 to $49.09, \mathrm{df}=(2,870), \mathrm{p}=0.000)$. For learning in the clinical setting, nurses' self-reported PS competence around Working in teams with other HPs is significantly lower than the MD and postgraduate medicine groups $(F(\mathrm{df}=3,1091) F=7.008$, $\mathrm{df}=(3,1091), \mathrm{p}=0.000)$; however, nurses' scores are significantly higher than both physician groups on all other dimensions $(F(3,1091) \mathrm{F}$ ranges from 7.03 to $17.64, \mathrm{df}=(3,1091), \mathrm{p}=0.000)$ except Communicating effectively, for which there are no significant differences between any of the groups. The teamwork dimension is explored in more detail below.

\section{Differences in self-reported PS competence in different learning settings}

Paired $t$ tests were used to compare confidence in PS learning in the class versus clinical setting. The trend in the data for the pharmacy and MD groups is that confidence in PS learning was significantly higher for the clinical setting compared with the classroom setting ( $p<0.01$; see table 1 , columns $\mathrm{D}$ and $\mathrm{E}$ ) with a few exceptions shown in bold text: pharmacists' scores based on the classroom and clinical setting learning did not differ on the Communicating effectively dimension, and MDs' self-reported confidence in PS learning regarding a Culture of safety did not differ from the class to clinical setting. Nurses were the only group to report significantly lower levels of confidence in learning in the clinical setting than the classroom setting and this was true for the dimensions Working in teams with other HPs, Communicating

Table 1 Items in the managing safety risks dimension

\begin{tabular}{|c|c|c|c|c|c|c|}
\hline & A & B & $\mathrm{C}$ & D & E & $F$ \\
\hline Dimension & $\begin{array}{l}\text { Learning } \\
\text { setting }\end{array}$ & $\begin{array}{l}\text { All HP groups } \\
\mathrm{N}=1102\end{array}$ & $\begin{array}{l}\text { Nursing } \\
\mathrm{N}=520\end{array}$ & $\begin{array}{l}\text { Pharmacy } \\
N=120\end{array}$ & $\begin{array}{l}\mathrm{MD} \\
\mathrm{N}=236\end{array}$ & $\begin{array}{l}\text { Postgrad. med. } \\
\mathrm{N}=226\end{array}$ \\
\hline Working in teams with other HPs & $\begin{array}{l}\text { Clinical } \\
\text { Class }\end{array}$ & $\begin{array}{l}3.72 \\
3.74\end{array}$ & $\begin{array}{l}3.62^{*} \\
3.89^{* *}\end{array}$ & $\begin{array}{l}3.67 \\
3.33^{* *}\end{array}$ & $\begin{array}{l}3.84 \\
3.61\end{array}$ & $\begin{array}{l}3.86 \\
\mathrm{n} / \mathrm{a}\end{array}$ \\
\hline Communicating effectively & $\begin{array}{l}\text { Clinical } \\
\text { Class }\end{array}$ & $\begin{array}{l}4.15 \\
4.12\end{array}$ & $\begin{array}{l}4.19 \\
4.26^{\text {** }}\end{array}$ & $\begin{array}{l}4.08 \\
4.04\end{array}$ & $\begin{array}{l}4.09 \\
3.86\end{array}$ & $\begin{array}{l}4.18 \\
\mathrm{n} / \mathrm{a}\end{array}$ \\
\hline Managing safety risks & $\begin{array}{l}\text { Clinical } \\
\text { Class }\end{array}$ & $\begin{array}{l}3.82 \\
3.55\end{array}$ & $\begin{array}{l}3.95^{*} \\
3.71^{* *}\end{array}$ & $\begin{array}{l}3.80 \\
3.40\end{array}$ & $\begin{array}{l}3.62 \\
3.27\end{array}$ & $\begin{array}{l}3.72 \\
\mathrm{n} / \mathrm{a}\end{array}$ \\
\hline $\begin{array}{l}\text { Understanding human and environmental factors } \\
\text { that influence PS }\end{array}$ & $\begin{array}{l}\text { Clinical } \\
\text { Class }\end{array}$ & $\begin{array}{l}3.84 \\
3.75\end{array}$ & $\begin{array}{l}4.04^{*} \\
4.00^{* *}\end{array}$ & $\begin{array}{l}3.92 \\
3.32\end{array}$ & $\begin{array}{l}3.59 \\
3.42\end{array}$ & $\begin{array}{l}3.61 \\
\mathrm{n} / \mathrm{a}\end{array}$ \\
\hline $\begin{array}{l}\text { Recognise and respond to remove immediate } \\
\text { risks of harm }\end{array}$ & $\begin{array}{l}\text { Clinical } \\
\text { Class }\end{array}$ & $\begin{array}{l}4.02 \\
3.79\end{array}$ & $\begin{array}{l}4.14^{*} \\
3.92^{* *}\end{array}$ & $\begin{array}{l}3.98 \\
3.71\end{array}$ & $\begin{array}{l}3.89 \\
3.54\end{array}$ & $\begin{array}{l}3.92 \\
\mathrm{n} / \mathrm{a}\end{array}$ \\
\hline $\begin{array}{l}\text { Culture of safety (feel safe to speak up/ } \\
\text { understand system nature of PS problems) }\end{array}$ & $\begin{array}{l}\text { Clinical } \\
\text { Class }\end{array}$ & $\begin{array}{l}3.84 \\
3.91\end{array}$ & $\begin{array}{l}3.95^{*} \\
4.07^{* *}\end{array}$ & $\begin{array}{l}3.85 \\
3.59\end{array}$ & $\begin{array}{l}3.69 \\
3.70\end{array}$ & $\begin{array}{l}3.73 \\
\mathrm{n} / \mathrm{a}\end{array}$ \\
\hline
\end{tabular}

*Significant within learning setting compared with both medicine groups.

** Significant within learning setting compared with other HP groups.

$H P$, health professional; PS, patient safety. 
Table 2 Items in the Managing safety risks dimension

\begin{tabular}{|c|c|c|c|c|c|}
\hline \multirow[b]{2}{*}{ 'I feel confident in what I learned about...' } & \multirow[b]{2}{*}{ Learning setting } & \multicolumn{4}{|c|}{$\%$ agree/strongly agree } \\
\hline & & Nursing & Pharmacy & MD & Postgraduate medicine \\
\hline Q14. Recognising routine situations in which safety problems may arise & $\begin{array}{l}\text { Class } \\
\text { Clinical }\end{array}$ & $\begin{array}{l}73.4 \\
83.5\end{array}$ & $\begin{array}{l}61.0 \\
82.5\end{array}$ & $\begin{array}{l}53.0 \\
69.9\end{array}$ & 76.4 \\
\hline Q15. Identifying and implementing safety solutions & $\begin{array}{l}\text { Class } \\
\text { Clinical }\end{array}$ & $\begin{array}{l}67.2 \\
73.1\end{array}$ & $\begin{array}{l}48.7 \\
72.0\end{array}$ & $\begin{array}{l}43.3 \\
54.5\end{array}$ & 59.1 \\
\hline Q16. Anticipating and managing high-risk situations & $\begin{array}{l}\text { Class } \\
\text { Clinical }\end{array}$ & $\begin{array}{l}56.9 \\
72.0\end{array}$ & $\begin{array}{l}45.8 \\
63.0\end{array}$ & $\begin{array}{l}41.0 \\
57.4\end{array}$ & 63.6 \\
\hline
\end{tabular}

effectively and Culture of safety (italic text in table 1 ) ( $\mathrm{t}=-6.2$ to $-2.4, \mathrm{df}=515, \mathrm{p}=0.000$ ti 0.017 ). Nurses' self-reported confidence in PS learning on the Understanding human factors dimension did not differ for the classroom and clinical setting.

The trend of different levels of confidence for learning in the clinical setting compared with learning in the classroom setting was explored in greater detail by looking at specific items. ${ }^{20}$ For the Managing safety risks dimension table 2 shows that the clinical setting equips all groups with far more confidence in learning on each of these items. In addition, a comparison of the MD and postgraduate medicine scores suggests increasing confidence with a longer period in the clinical setting. This result is consistent with reported data for this dimension gathered from nursing students in different years of an undergraduate nursing programme. ${ }^{38}$

A focus on individual items is also useful for more closely examining the dimension Working in teams with other HPs. Table 1 indicates that the Working in teams with other HPs dimension scores lower than many or all dimensions across all four groups. In addition, the only instance when nurses' level of confidence in learning is significantly lower than any of the other HP groups we examined is for learning in the clinical setting related to Working in teams with other
HPs. Furthermore, nurses' confidence in learning related to Working in teams with other HPs is not only significantly lower for learning in the clinical setting than for learning in the classroom setting but the magnitude of this difference is important (Cohen's $d=0.33$, which is a small to medium effect size). ${ }^{39}$ Figure 1 shows the percentage of respondents in each HP group who agree with each of the three items in this dimension. On items 9 and 10,12\% and $20 \%$ fewer nurses were confident following clinical learning than classroom learning. In contrast, pharmacists and postgraduates expressed far greater confidence in learning on all three items as they move from thinking about classroom learning to learning in the clinical setting. Online appendix 1 shows all of the items in each dimension and the percentage of respondents in each HP group who agreed or strongly agreed with each question.

\section{DISCUSSION}

This study examined self-reported PS competence among newly registered/licensed nurses, pharmacists and physicians. In this study self-reported PS competence is operationalised as level of confidence in learning about six socio-cultural dimensions of PS. Here we discuss three key findings. First, the overall levels of confidence in PS learning we found are consistent

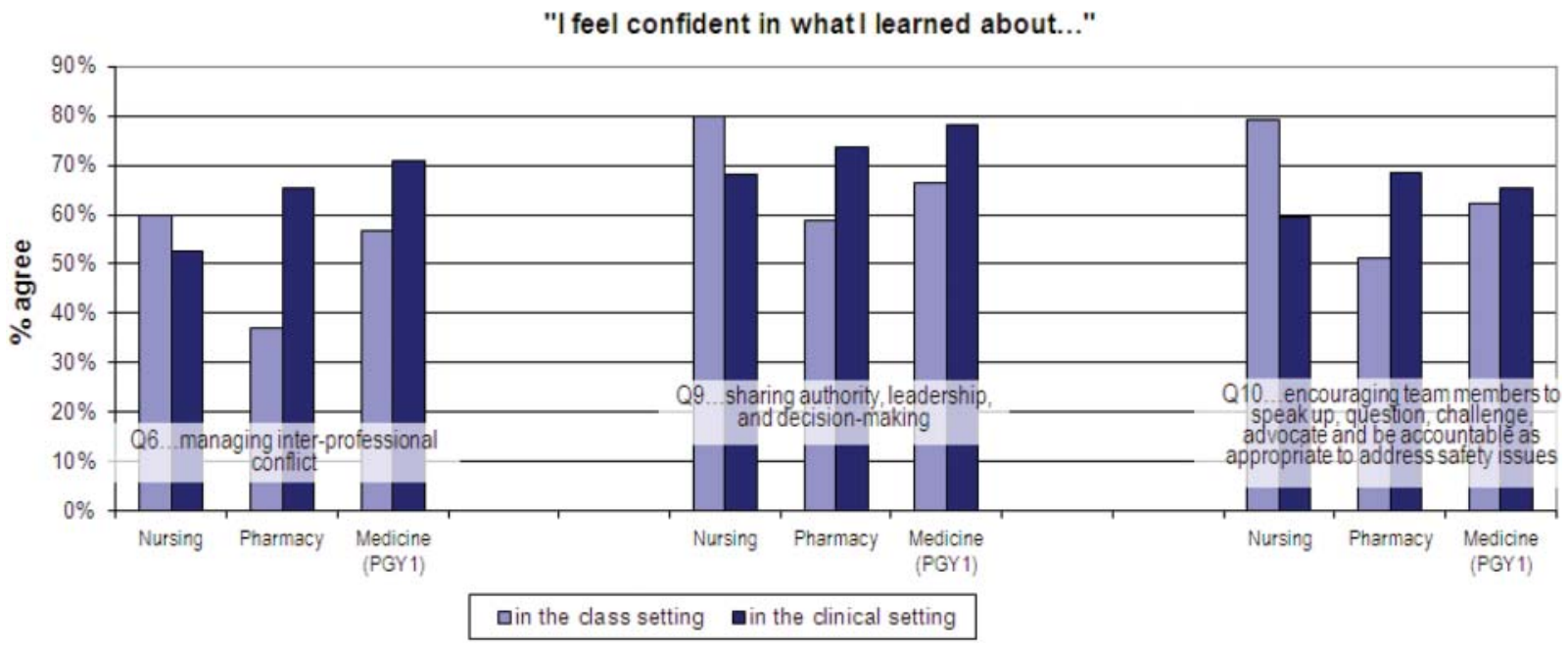

Figure 1 Items in the Working in teams with other health professionals dimension. PGY1, postgraduate year 1. 
with other research with physicians, indicating that more training in how to handle errors is required. ${ }^{40}$ In addition, our results show lower levels of confidence in PS learning around the dimensions of Managing safety risks and Understanding human and environmental factors that influence PS—a finding that underscores the need to introduce concepts from 'safety science' into HP education. ${ }^{41}$

Second, our results show nurses scored significantly higher than the pharmacy and MD groups on all H-PEPSS dimensions for learning in the classroom setting, and on most dimensions for learning in the clinical setting. Different studies that have asked different HP trainees the same question (about the extent to which 'the culture of medicine makes it easy for providers to deal constructively with errors') also show far more positive scores for nurse trainees 2526 compared with physician trainees. ${ }^{17}$ Other work ${ }^{27}$ has also found medical students' self-reported baseline PS knowledge scores were significantly lower than those of nurses and respiratory therapists. While interesting, these kinds of absolute differences in levels of confidence in PS learning across different HP groups may reflect a number of factors, including differences in professional beliefs entrenched within the culture of learning ${ }^{42} 43$ or HP group differences in levels of 'not knowing what one doesn't know'. Accordingly, this is an area in need of further study.

Third, our results showing differences in PS learning confidence across learning settings have interesting implications. The trend in our data was that the pharmacy and physician groups reported significantly higher confidence in PS learning following experience in the clinical setting compared with the classroom setting. This is consistent with work showing that opportunities for learners to practically apply PS material leads to greater PS confidence. ${ }^{16}$ However, our findings for nurses did not adhere to this pattern on the H-PEPSS dimensions Working in teams with other HPs, Communicating effectively, and Culture of safety. Instead, nurses' confidence in learning on these dimensions worsened (while physician's confidence improved) as they moved from thinking about learning in the classroom setting to learning in the real world of the clinical setting. These findings suggest that, for nurses, there is an important contextual influence of training in the clinical setting that weakens their confidence in some of the key socio-cultural aspects of PS. These results fit with recent work which showed declining confidence in PS teamwork learning among nurses in later years of an undergraduate nursing programme $^{38}$ and with work in intensive care units, ${ }^{44}$ operating rooms ${ }^{45} 46$ and general medicine wards, ${ }^{47}$ showing that nurses' perceptions of collaboration and communication with physicians are less positive than physicians' perceptions.

Indeed, the hierarchical nature of healthcare, power imbalances between physicians and nurses ${ }^{48}$ reflected in differing perceptions of and responses to conflict between these two HP groups, ${ }^{49}$ and aspects of the overall culture (recently described as disrespectful and demeaning in its treatment of nurses) ${ }^{50}$ may be important contributing factors to nurses' deteriorating confidence in learning about Working in teams, Communicating effectively and the Culture of safety in the clinical setting. Similarly, the role and influence of the hidden curriculum may also help to explain why our nursing group had less confidence in their teamwork and communication skills after training in the clinical setting. The hidden curriculum, which is a set of influences or unintended messages that function at an institutional and cultural level, ${ }^{51}$ is well understood to be a potential source of the disconnect between what is learned in the classroom versus what is experienced in the clinical setting. Moreover, the literature is replete with instances of within-profession faculty-learner incivility in nursing ${ }^{52}$ and in medicine. ${ }^{53} 54$

The generally harmful nature of the hierarchical culture that typifies the clinical settings in which we train HPs is also well documented ${ }^{50-57}$ and may explain the lower levels of confidence in teamwork and communication learning among nurses as they moved into the clinical setting. Ultimately, HP trainees are highly influenced by their faculty preceptors' attitudes towards PS and the PS culture of the teaching organisations in which they learn. ${ }^{20} 58$ Accordingly, it is crucial that the informal curriculum (eg, the ad hoc, personal form of teaching) and the hidden curriculum are well understood to try to exploit all educational venues and positively influence HP training programmes. ${ }^{32} 59$

Inter-professional education may be useful for responding to lower levels of confidence in teamwork and communication learning that nurses experience as they move into the clinical setting. Inter-professional training opportunities at different stages of the educational process can address harmful effects of hierarchical power dynamics that exist between nurses and physicians $^{28} 6061$ and can generate positive attitudes toward inter-professional collaboration early in training. ${ }^{62}$ While inter-professional learning opportunities remain limited, ${ }^{63}$ there is some recent empirical work that suggests trainees value learning in interprofessional environments, ${ }^{64}$ that it can improve teamwork knowledge and attitudes, ${ }^{29} 62$ and that it can resolve differences in PS viewpoints held by different groups of HP trainees. ${ }^{27}$ While some suggest that inter-professional education delivered using case studies and simulation are more likely to be successful than didactic lectures alone, ${ }^{41} 65$ more recent work found that costlier modalities of delivery were not necessarily found to be superior. ${ }^{29}$

Finally, as we consider approaches to more deeply and consistently embed learning about the sociocultural aspects of PS it will be important to recognise that the clinical setting is complex and there are 
various factors that influence what is being learned and how. ${ }^{66}$ In addition, learning opportunities in the clinical setting rub up against the reality of competing educational demands ${ }^{9}$ and overburdened clinicians who have limited time to devote to teaching and learning. ${ }^{25}$ The need for greater numbers of clinical faculty who are familiar with quality improvement and PS content, ${ }^{1496768}$ and closer links between academic staff in universities and managers in healthcare settings around PS have been suggested and may help to achieve an appropriate balance of learning in these two settings. ${ }^{31} 69$

This study has some limitations. First, the selfreported nature of the data mean that some degree of social desirability bias is likely and the absolute levels of confidence in PS learning that are reported, when they are high, may reflect that respondents are unaware of what they do not know. Similarly, trainees may overestimate or underestimate their PS competence. For these reasons we focus more on the data patterns than the absolute levels of self-reported PS competence. Second, while response rates in the 30\% range are typical in these kinds of surveys, the nature of any potential non-response bias remains unclear. Further research, perhaps qualitative, is required to better understand why nurses' confidence in learning around inter-professional teamwork weakens when they learn in the clinical setting.

\section{CONCLUSIONS}

As efforts to enhance PS in HP education continue, it is important to recognise that PS in HP education still largely reflects clinical safety (eg, attention to infection control and medication safety ${ }^{31}$ ). This should not be surprising given that most HP curricula that include PS devote at most a few hours to the topic. ${ }^{9}{ }^{70}$ Large-scale efforts are required to more deeply and consistently embed PS learning into HP education. However, such efforts require attention to a number of factors at the level of the learner, the faculty and the clinical learning setting. In particular, this study reveals that efforts to embed PS learning in HP education may be hampered by fairly profound deficiencies that persist in the culture of the clinical training environments in which we educate and, paradoxically, acculturate our new HPs.

Acknowledgements The authors wish to thank Heather Campbell, RN (formerly with the College of Nurses of Ontario), Dan Faulkner from the College of Physicians and Surgeons of Ontario, Shenda Tanchak (formerly with the College of Physicians and Surgeons of Ontario), and Della Croteau and Anne Resnick from the Ontario College of Pharmacists for their support and for their help with sampling and data collection. We also wish to thank Brett Thompson and Christopher Chan for their help with data collection.
Contributors LG designed the study (including data collection tools and methods), monitored data collection, cleaned and analysed the data, and drafted and revised the paper. She is guarantor. DT and PGN contributed to overall study design and revising and approving the manuscript.

Funding This study was funded by a research grant from the Canadian Patient Safety Institute, RFA09-1181-ON.

\section{Competing interests None.}

Ethics approval The study received approval from the Human Participants Review Committee in the Office of Research Ethics at York University.

Provenance and peer review Not commissioned; externally peer reviewed.

Data sharing statement Data may be available on request from the corresponding author.

Open Access This is an Open Access article distributed in accordance with the Creative Commons Attribution Non Commercial (CC BY-NC 3.0) license, which permits others to distribute, remix, adapt, build upon this work non-commercially, and license their derivative works on different terms, provided the original work is properly cited and the use is noncommercial. See: http://creativecommons.org/licenses/ by-nc/3.0/

\section{REFERENCES}

1 Lucian Leape Institute. Unmet Needs: Teaching Physicians to Provide Safe Patient Care. Boston, MA: National Patient Safety Foundation, 2010.

2 Department of Health. Modernising Medical Careers. The New Curriculum for the Foundation Years in Postgraduate Education and Training. London, UK: Department of Health, 2007.

3 American Association of Colleges of Nursing. Hallmarks of quality and patient safety: recommended baccalaureate competencies and curricular guidelines to ensure high-quality and safe patient care. J Prof Nurs 2006;22:329-30.

4 Cronenwett L, Sherwood G, Barnsteiner J, et al. Quality and safety education for nurses. Nurs Outlook 2007;55:122-31.

5 Frank JR, Brien S, on behalf of The Safety Competencies Steering Committee. The Safety Competencies: Enhancing Patient Safety Across the Health Professions. Ottawa, ON: Canadian Patient Safety Institute, 2008.

6 Schumacher DJ, Slovin SR, Riebschleger MP, et al. Perspective: beyond counting hours: the importance of supervision, professionalism, transitions of care, and workload in residency training. Acad Med 87(7):883-8. Published Online First 22 May 2012. doi:10.1097/ACM.0b013e318257d57d.

7 Bloom SW. The medical school as a social organization: the sources of resistance to change. Med Educ 1989;23:228-41.

8 Nie Y, Li L, Duan Y, et al. Patient safety education for undergraduate medical students: a systematic review. BMC Med Educ 2011;11:33.

9 Wong BM, Etchells EE, Kuper A, et al. Teaching quality improvement and patient safety to trainees: a systematic review. Acad Med 2010;85:1425-39. 
10 Kane JM. Patient safety education: overreported and still lacking. Acad Med 2010;85:1397-8.

11 Alper E, Rosenberg E, O'Brien KE, et al. Patient safety education at U.S. and Canadian medical Schools: results from the 2006 Clerkship Directors in Internal Medicine Survey. Acad Med 2009;84:1672-6.

12 Castel E, Ginsburg L. Patient Safety in Health Professional Education: Development of a Questionnaire to Assess Student Learning. Report to the Canadian Patient Safety Institute. 2008. http://www.yorku.ca/patientsafety/H-PEPSS/ 2008 _pilot_Ginsburg\%20\&\%20Castel $\% 20$ Safety $\%$ 20Competencies\%20Studentship\%20Final\%20Report.pdf (accessed 23 october 2012).

13 Aboumatar HJ, Thompson D, Wu A, et al. Development and evaluation of a 3-day patient safety curriculum to advance knowledge, self-efficacy and system thinking among medical students. BMJ Qual Saf 2012;21:416-22.

14 Debourgh GA. Synergy for patient safety and quality: academic and service partnerships to promote effective nurse education and clinical practice. J Prof Nurs 2012;28:48-61.

15 Jansma JD, Wagner C, ten Kate RW, et al. Effects on incident reporting after educating residents in patient safety: a controlled study. BMC Health Serv Res 2011;11:335.

16 Halbach JL, Sullivan LL. Teaching medical students about medical errors and patient safety: evaluation of a required curriculum. Acad Med 2005;80:600-6.

17 Madigosky WS, Headrick LA, Nelson K, et al. Changing and sustaining medical students' knowledge, skills, and attitudes about patient safety and medical fallibility. Acad Med 2006;81:94-101.

18 Gunderson AJ, Smith KM, Mayer DB, et al. Teaching medical students the art of medical error full disclosure: evaluation of a new curriculum. Teach Learn Med 2009;21:229-32.

19 Leung GK, Patil NG, Ip MS. Introducing patient safety to undergraduate medical students-a pilot program delivered by health care administrators. Med Teach 2010;32:e547-51.

20 Vohra PD, Johnson JK, Daugherty CK, et al. Housestaff and medical student attitudes toward medical errors and adverse events. Jt Comm J Qual Saf 2007;33:493-501.

21 Carruthers S, Lawton R, Sanders J, et al. Attitudes to patient safety amongst medical students and tutors: Developing a reliable and valid measure. Med Teach 2009;31:e370-6.

22 Flin R, Patey R, Jackson J, et al. Year 1 medical undergraduates' knowledge of and attitudes to medical error. Med Educ 2009;43:1147-55.

23 Miller CL, LaFramboise L. Student learning outcomes after integration of quality and safety education competencies into a senior-level critical care course. J Nurs Educ 2009;48:678-84.

24 Sullivan DT, Hirst D, Cronenwett L. Assessing quality and safety competencies of graduating prelicensure nursing students . Nurs Outlook 2009;57:323-31.

25 Ardizzone LL, Enlow WM, Evanina EY, et al. Impact of a patient safety curriculum for nurse anesthesia students. J Nurs Educ 2009;48:706-10.

26 Schnall R, Stone P, Currie L, et al. Development of a self-report instrument to measure patient safety attitudes, skills, and knowledge. J Nurs Scholarsh 2008;40:391-4.

27 Cox KR, Scott SD, Hall LW, et al. Uncovering differences among health professions trainees exposed to an interprofessional patient safety curriculum. Qual Manag Health Care 2009;18:182-93.

28 Anderson E, Thorpe L, Heney D, et al. Medical students benefits from learning about patient safety in an interprofessional team. Med Educ 2009;43:542-52.
29 Hobgood C, Sherwood G, Frush K, et al. Teamwork training with nursing and medical students: does the method matter? Results of an interinstitutional, interdisciplinary collaboration. Qual Saf Health Care 2010;19:e1-6.

30 Weller JM, Barrow M, Gasquoine S. Interprofessional collaboration among junior doctors and nurses in the hospital setting. Med Educ 2011;45:478-87.

31 Pearson P, Steven A, Howe A, et al. Learning about patient safety: organizational context and culture in the education of health care professionals. J Health Serv Res Policy 2010;15(Suppl 1):4-10.

32 Pingleton SK, Davis DA, Dickler RM. Characteristics of quality and patient safety curricula in major teaching hospitals. Am J Med Qual 2010;25:305-11.

33 Ginsburg L, Castel E, Tregunno D, et al. The H-PEPSS: an instrument to measure health professionals' perceptions of patient safety competence at entry into practice. BMJ Qual Saf 2012;21:676-84.

34 Dillman DA, Smyth JD, Christian LM. Internet, Mail, and Mixed-mode Surveys: The Tailored Design Method. 3rd edn. Hoboken, NJ: Wiley \& Sons, 2009.

35 Walton MM, Shaw T, Barnet S, et al. Developing a national patient safety education framework for Australia. Qual Saf Health Care 2006;15:437-42.

36 Walton M, Woodward H, Staalduinen SV, et al. The WHO patient safety curriculum guide for medical schools. Qual Saf Health Care 2010;19:542-6.

37 Okuyama A, Martowirono K, Bijnen B. Assessing the patient safety competencies of healthcare professionals: a systematic review. BMJ Qual Saf 2011;20:991-1000.

38 Duhn L, Karp S, Oni O, et al. Perspectives on patient safety among undergraduate nursing students. J Nurs Educ 2012;51:526-31.

39 Cohen J. Statistical Power Analysis for the Behavioral Sciences. New York: Academic Press, 1988.

40 Wears RL, Wu AW. Dealing with failure: the aftermath of errors and adverse events. Ann Emerg Med 2002;39:344-6.

41 Croskerry P, Wears RL, Binder LS. Setting the educational agenda and curriculum for error prevention in emergency medicine. Acad Emerg Med 2000;7:1194-200.

42 Hall P. Interprofessional teamwork: professional cultures as barriers. J Interprof Care 2005;19(Suppl 1):188-96.

43 Barker KK, Bosco C, Oandasan IF. Factors in implementing interprofessional education and collaborative practice initiatives: findings from key informant interviews. J Interprof Care 2005;19(Suppl 1):166-76.

44 Thomas EJ, Sexton JB, Helmreich RL. Discrepant attitudes about teamwork among critical care nurses and physicians. Crit Care Med 2003;31:956-9.

45 Wauben LS, Dekker-van Doorn CM, van Wijngaarden JD, et al. Discrepant perceptions of communication, teamwork and situation awareness among surgical team members. Int J Qual Health Care 2011;23:159-66.

46 Mills P, Neily J, Dunn E. Teamwork and communication in surgical teams: implications for patient safety. J Am Coll Surg 2008;206:107-12.

47 O'Leary KJ, Ritter CD, Wheeler H, et al. Teamwork on inpatient medical units: assessing attitudes and barriers. Qual Saf Health Care 2010;19:117-21.

48 Sundin-Huard D. Subject positions theory-its application to understanding collaboration (and confrontation) in critical care. J Adv Nurs 2001;34:376-82. 
49 Skjorshammer M. Co-operation and conflict in a hospital: interprofessional differences in perception and management of conflicts. J Interprof Care 2001;15:7-18.

50 Leape LL, Shore MF, Dienstag JL, et al. Perspective: a culture of respect, part 1: the nature and causes of disrespectful behavior by physicians. Acad Med 2012;87:845-52.

51 Hafferty FW. Beyond curriculum reform: confronting medicine's hidden curriculum. Acad Med 1998;73:403-7.

52 Del Prato D. Students' voices: the lived experience of faculty incivility as a barrier to professional formation in associate degree nursing education. Nurse Educ Today. Published Online First 20 June 2012. doi:10.1016/j.nedt.2012.05.030. Epub ahead of print

53 Fried JM, Vermillion M, Parker NH, et al. Eradicating medical student mistreatment: a longitudinal study of one institution's efforts. Acad Med 2012;87:1191-8.

54 Benbassat J. Undesirable features of the medical learning environment: a narrative review of the literature. Adv Health Sci Educ Theory Pract. Published Online First 4 July 2012. doi: 10.1007/s10459-012-9389-5. Epub ahead of print

55 Gregory DM, Guse LW, Dick DD, et al. Patient safety: where is nursing education? J Nurs Educ 2007;46:79-82.

56 Chenot TM, Daniel LG. Frameworks for patient safety in the nursing curriculum. J Nurs Educ 2010;49:559-68.

57 Attree M, Cooke H, Wakefield A. Patient safety in an English pre-registration nursing curriculum. Nurse Educ Pract $2008 ; 8: 239-48$.

58 Aaron DC, Headrick LA. Educating physicians prepared to improve care and safety is no accident: it requires a systematic approach. Qual Saf Health Care 2002;11:168-73.

59 Bradley F, Steven A, Ashcroft DM. The role of hidden curriculum in teaching pharmacy students about patient safety. Am J Pharm Educ 2011;75:143.

60 Chakraborti C, Boonyasai RT, Wright SM, et al. A systematic review of teamwork training interventions in medical student and resident education. J Gen Intern Med 2008;23: 846-53.

61 Jain A, Luo E, Yang J, et al. Implementing a nurse-shadowing program for first-year medical students to improve interprofessional collaborations on health care teams. Acad Med 2012;87:1292-5.

62 Wamsley M, Staves J, Kroon L, et al. The impact of an interprofessional standardized patient exercise on attitudes toward working in interprofessional teams. J Interprof Care 2012;26:28-35.

63 Kiersma ME, Plake KS, Darbishire PL. Patient safety instruction in US health professions education. Am J Pharm Educ 2011;75:162.

64 Abbott AA, Fuji KT, Galt KA, et al. How baccalaureate nursing students value an interprofessional patient safety course for professional development. ISRN Nurs. Published Online First 14 March 2012. doi: 10.5402/2012/401358. Epub ahead of print

65 Morgan PJ, Cleave-Hogg D. Simulation technology in training students, residents and faculty. Curr Opin Anaesthesiol 2005;18:199-203.

66 de Feijter JM, de Grave WS, Dornan T, et al. Students' perceptions of patient safety during the transition from undergraduate to postgraduate training: an activity theory analysis. Adv Health Sci Educ Theory Pract 2010;16:347-58.

67 Wong BM, Levinson W, Shojania KG. Quality improvement in medical education: current state and future directions. Med Educ 2012;46:107-19.

68 Thornlow DK, McGuinn K. A necessary sea change for nurse faculty development: spotlight on quality and safety. J Prof Nurs 2010;26:71-81.

69 Fleischut PM, Evans AS, Nugent WC, et al. Perspective: call to action: it is time for academic institutions to appoint a resident quality and patient safety officer. Acad Med 2011;86:826-8.

70 Maeda S, Kamishiraki E, Starkey J. Patient safety education at Japanese medical schools: results of a nationwide survey. BMC Res Notes 2012;5:226. 